\title{
Finite Element Analysis of Piezoelectric Functionally Graded Materials with the variation of volume fraction index
}

\author{
Aunyamanee Chadajit ${ }^{\mathrm{a}}$, Veena Phunpeng ${ }^{\mathrm{b}, *}$ \\ ${ }^{a}$ Mechatronics Engineering, Suranaree University of Technology, Nakhonratchasima and 30000, THAILAND \\ ${ }^{\mathrm{b}}$ Mechanical Engineering, Suranaree University of Technology, Nakhonratchasima and 30000, THAILAND \\ *Corresponding Author: veenap@g.sut.ac.th
}

\begin{abstract}
In this paper, the material properties of functionally graded piezoelectric materials (FGPMs) are investigated. Variations through the beam thickness under electromechanical loads by applying Euler-Bernoulli Beam Theory (EBT) and Timoshenko beam Theory (TBT) are investigated Results from standard FEM using Lagrange and Hermite polynomial shape functions are reported and compared with those from standard FEM based on different beam theories. The FEM discretization employed to investigate FGPMs shows an excellent agreement with available results in the literature, with the results being in close agreement with those obtained from Aldrahem and Khdeir (1999) using first order beam theory (FOBT). FEM has therefore been shown to be an excellent tool for investigating FGPMs, with advantages over previously used methods including a high efficiency due to the large class of finite element discretizations available that are tailored to particular applications.
\end{abstract}

Keywords: Finite element method, functionally graded beam, piezoelectric materials, volume fraction index

\section{Introduction}

At present, piezoelectric materials are a widely used material in electrical device industries, especially for power energy storage, actuators exhibiting high reliability and performance. Functionally graded piezoelectric materials (FGPMs) are a material type in which the material properties vary through the thickness of the material. Their material properties can vary continuously through the thickness direction according to a simple power law distribution [10]:

$$
P(z)=\left(P_{t}-P_{b}\right)\left(\frac{z}{h}+\frac{1}{2}\right)^{n}+P_{b}
$$

where $P$ is a material property at any point, $P_{t}$ and $P_{b}$ are the material properties on the top surface and the bottom surface, $z$ is a position in the thickness direction, $\mathrm{h}$ is the thickness and $n$ is the volume fraction index of the FGPMs. The smooth variation of their properties along the $\mathrm{z}$ direction allows a greater range of deformation and thus induced electrical potential, without the extra stress concentration associated with a sharp boundary.

In 2011, Komeili et al. [1] analyzed the static bending of beams made of functionally graded piezoelectric materials (FGPMs) under a combined thermos - electro - mechanical load. The Euler Bernoulli theory (EBT), first-order shear deformation theory (FSDT) and third-order shear deformation theory (TSDT) were employed to compare the accuracy and the reliability of each theory in applications by varying material properties continuously through the thickness direction. In 2007, Yang and Xiang [2] investigated the static bending, free vibration, and dynamic response of actuators made of FGPMs under a combined thermal-electromechanical load by using the Timoshenko beam theory. In 2013, Wang J. et al., [3] analysis of piezoelectric beam-type transducers with interlayer slip based on the Euler-Bernoulli beam theory. X.Q. Hea et al (2001) [4] presented for the shape and vibration control of the functionally graded material (FGM) plates with integrated piezoelectric sensors and actuators under electro-mechanical loads by using the finite 
element method associated with the approximation of Lagrange and Hermite shape functions. In 2001 TY. Ng et al., [5] considered FGM plate with the integrated sensors and actuators by using the classical laminated plate theory which can extended to higher order laminated plate theory. In 2012, B.C.L. Vanam et al., [6] carried out for an isotropic rectangular plate by considering the master element as a four node quadrilateral element from numerical analysis (finite element analysis, FEA) by developing programming in mathematical software MATLAB. L.F. Greimann and P.P. Lynn (1970) [7] investigated plate bending which include transverse shear deformation from Mindlin's plate theory included considering on plate thickness

In this paper, Euler-Bernoulli Beam Theory (EBT) and Timoshenko beam Theory (TBT) are used to investigate functionally graded piezoelectric beams (FGPBs) with a variation of volume fraction index. Results from standard FEM using Lagrange and Hermite polynomial shape functions are reported and compared with those from standard FEM based on different beam theories. The properties investigated include the deflections and electrical potential variations within the material. Furthermore, the effect of the volume fraction index and slenderness ratios $(\mathrm{L} / \mathrm{h})$ are investigated and compared with numerical solutions from the literature.

\section{Formulation}

The Euler-Bernoulli beam theory assumes that underformed plane sections remain planar under deformation, in contrast to Timoshenko beam theory. The formulation accounts for transverse shear deformation and assumes the deformed cross-section planes remain planar..

\subsection{Euler-Bernoulli Beam Theory (EBT)}

The equation for bending [8] given by EBT, when $\mathrm{P}$ is a distribution load, $\mathrm{E}$ is the elastic modulus and $\mathrm{I}$ is the second moment of area, is:

$$
\frac{d^{2}}{d x^{2}}\left(-E I \frac{d^{2} w}{d x^{2}}\right)-\mu \frac{d^{2} P}{d x^{2}}+P=0
$$

The deflection solution along $\mathrm{x}$ direction is [9]

$$
w^{E}(x)=\frac{P x}{24 E I}\left(L^{3}-2 L x^{2}+x^{3}\right)
$$

(a) Simply supported beams

The Boundary conditions for a simply supported beam are $w^{E}=0, M^{E}=0$ at $x=0$ and $w^{E}=0, M^{E}=0$ at $x=a$. Under these conditions, the deflection solution is then:

$$
w^{E}(x)=\frac{P L^{4}}{24 E I}\left(\frac{x^{4}}{L^{4}}-2 \frac{x^{3}}{L^{3}}+\frac{x}{L}\right)
$$

(b) Cantilever beams

The Boundary conditions for Cantilever beams are at $w=0, d w^{E} / d x=0$ at $x=0$ and $w^{E}=0, M^{E}=0$ at $x=a$. Under these conditions, the deflection solution is then:

$$
w^{E}(x)=\frac{P L^{4}}{24 E I}\left(\frac{x^{4}}{L^{4}}-4 \frac{x^{3}}{L^{3}}+6 \frac{x^{2}}{L^{2}}\right)
$$

\subsection{Timoshenko Beam Theory (TBT)}

The equation for bending [8] given by TBT is,

$$
\frac{d}{d x}\left(E I \frac{d \phi^{T}}{d x}\right)-G A K_{s}\left(\phi^{T}+\frac{d w^{T}}{d x}\right)=0
$$

(c) Simply supported beams

The Boundary conditions for a simply supported beam are $w^{E}=0, M^{E}=0$ at $x=0$ and $w^{E}=0, M^{E}=0$ at $x=a$. Under these conditions, the deflection solution is then:

$$
w^{T}(x)=\frac{P L^{4}}{24 E I}\left(\frac{x^{4}}{L^{4}}-2 \frac{x^{3}}{L^{3}}+\frac{x}{L}\right)+\frac{P L^{2}}{G A K_{s}}\left(-\frac{x^{2}}{2 L^{2}}+\frac{x}{L}\right)
$$

(d) Cantilever beams

The Boundary conditions for Cantilever beams are at $w=0, d w^{E} / d x=0$ at $x=0$ and $w^{E}=0, M^{E}=0$ at $x=a$. Under these conditions, the deflection solution is then:

$w^{T}(x)=\frac{P L^{4}}{24 E I}\left(\frac{x^{4}}{L^{4}}-4 \frac{x^{3}}{L^{3}}+6 \frac{x^{2}}{L^{2}}\right)+\frac{P L^{2}}{2 G A K_{s}}\left(\frac{x^{2}}{L^{2}}-2 \frac{x}{L}\right)$

For the numerical analysis using Finite Element Method (FEM), the piezoelectric constitutive equations for piezoelectric beams which are used to investigate the behaviour of composite materials are shown in Phunpeng et al. [10]. Following those equations and embedding the boundary condition of the simply supported beams and 
cantilever beams, the deformation when the beams subjected to electro-mechanical loads can be investigated.

\section{Results}

In this paper, we analyze functionally graded piezoelectric beams under a mechanical load by using EulerBernoulli Beam Theory (EBT) and Timoshenko beam Theory (TBT), varying the thickness of beams. The beam deflections are investigated using FEM, and the results of using EBT and TBT are compared. The deflections of the simply supported problem and cantilever problems are subjected to a uniform pressure of $1 \mathrm{kN} / \mathrm{m}^{2}$. The results are presented in Tables 1 to 4 .

Table 1. Beam deflection for simply supported using TBT.

\begin{tabular}{|c|c|c|c|c|}
\hline $\mathrm{h} / \mathrm{L}$ & $\begin{array}{c}\text { Exact } \\
\text { solution }\end{array}$ & $\begin{array}{c}\text { Deflection } \\
\text { solution }\end{array}$ & $\begin{array}{c}\text { Present } \\
\text { solution }\end{array}$ & \%difference \\
\hline 0.001 & 1.5625 & 1.5625 & 1.5623 & 0.013 \\
\hline 0.01 & 0.0016 & 0.0015631 & 0.00156 & 0.198 \\
\hline 0.1 & $1.62 \mathrm{E}-06$ & $1.62 \mathrm{E}-06$ & $1.59 \mathrm{E}-06$ & 1.852 \\
\hline
\end{tabular}

Table 2. Beam deflection for cantilever beam using TBT

\begin{tabular}{|c|c|c|c|c|}
\hline $\mathrm{h} / \mathrm{L}$ & $\begin{array}{c}\text { Exact } \\
\text { solution }\end{array}$ & $\begin{array}{c}\text { Deflection } \\
\text { solution }\end{array}$ & $\begin{array}{c}\text { Present } \\
\text { solution }\end{array}$ & \%difference \\
\hline 0.001 & 15 & 15 & 15 & 0.000 \\
\hline 0.01 & 0.015 & 0.015 & 0.015 & 0.000 \\
\hline 0.1 & $1.50 \mathrm{E}-05$ & $1.49 \mathrm{E}-05$ & $1.51 \mathrm{E}-05$ & 1.167 \\
\hline
\end{tabular}

Table 3. Beam deflection for simply supported using EBT

\begin{tabular}{|c|c|c|c|c|}
\hline $\mathrm{h} / \mathrm{L}$ & $\begin{array}{c}\text { Exact } \\
\text { solution }\end{array}$ & $\begin{array}{c}\text { Deflection } \\
\text { solution }\end{array}$ & $\begin{array}{c}\text { Present } \\
\text { solution }\end{array}$ & \%difference \\
\hline 0.001 & 1.5625 & 1.5625 & 1.5625 & 0.000 \\
\hline 0.01 & 0.1562 & 0.1562 & 0.1563 & 0.064 \\
\hline 0.1 & $1.56 \mathrm{E}-05$ & $1.56 \mathrm{E}-05$ & $1.26 \mathrm{E}-05$ & 1.852 \\
\hline
\end{tabular}

Table 4. Beam deflection for cantilever using EBT.

\begin{tabular}{|c|c|c|c|c|}
\hline $\mathrm{h} / \mathrm{L}$ & $\begin{array}{c}\text { Exact } \\
\text { solution }\end{array}$ & $\begin{array}{c}\text { Deflection } \\
\text { solution }\end{array}$ & $\begin{array}{c}\text { Present } \\
\text { solution }\end{array}$ & \%difference \\
\hline 0.001 & 1.5 & 1.5 & 1.5 & 0.000 \\
\hline 0.01 & 0.15 & 0.15 & 0.1499 & 0.067 \\
\hline 0.1 & $1.50 \mathrm{E}-04$ & $1.49 \mathrm{E}-05$ & $1.49 \mathrm{E}-05$ & 1.852 \\
\hline
\end{tabular}

In the above, the \%difference is defined as:
$\%$ difference $=\left(\frac{\text { Deflection solution }- \text { Present solution }}{\text { Deflection solution }}\right) * 100$

From Table 1 and 3, TBT and EBT theory was analyzed on simply support problem under uniform load. The results of \%different shows that the Exact solution is more accurately modelled by the Present solution at low $\mathrm{h} / \mathrm{L}$. Table 2 and 4 , shows \%different agreement on a cantilever problem under uniform load.

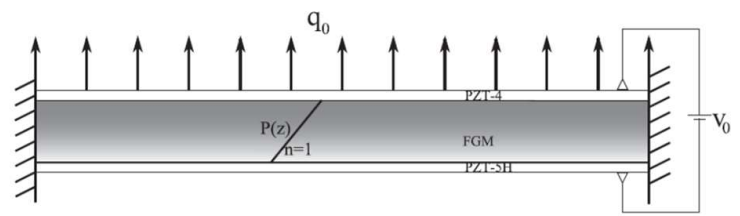

(a)

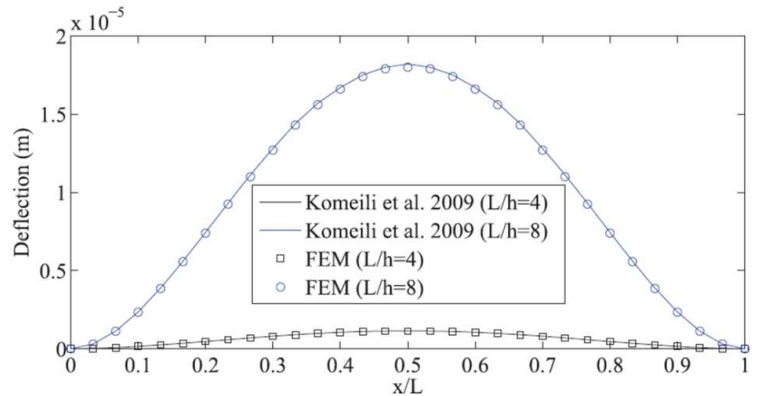

(b)

Figure 1 A simply-supported Piezoelectric monomorph beam with different aspect ratio

Figure 1 shows the transverse deflections of a simply supported FGPM beam subjected to a uniform pressure of 10 $\mathrm{kN} / \mathrm{m} 2$ and a voltage of $10 \mathrm{~V}$ with aspect ratio $\mathrm{L} / \mathrm{h}=4$ and $\mathrm{L} / \mathrm{h}$ $=8$.

Considering the same FGPM beam under different conditions: TBT and EBT, Figure 2 demonstrates a FGPM cantilever beam subjected to an electromechanical load. 


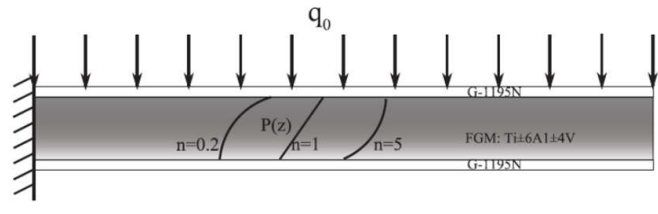

(a)

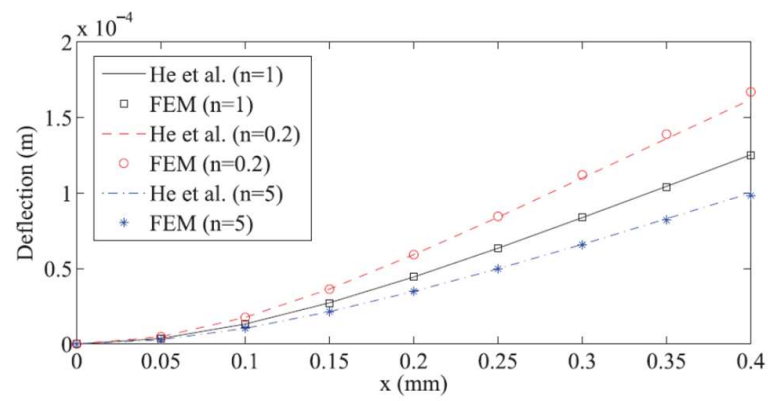

(b)

Figure 2 A cantilever Piezoelectric monomorph beam a) boundary condition $b$ ) with different volume fraction indices

Figure 2 shows the effect of the volume fraction index on the deflections of the cantilever beam. This means that the FGM properties are close to those of Ti-6A1-4V when $\mathrm{n}<1$. In all cases considered the aspect ratios (geometry), boundary conditions, material properties (including the effect of volume fraction indices) and discretization show an excellent agreement with available results in the open literature.

\section{Conclusions}

The deflections of the FGPM beam investigated using Euler-Bernoulli Beam Theory (EBT) and Timoshenko beam Theory (TBT) present a good agreement with results in the literature. The volume fraction index was shown to be an important feature of the material properties in order to provide different FGPM behaviors. This study can provide a method of investigating electro-mechanical systems of material analysis in order to predict the material behaviors In the future, the authors intend to use the techniques of this paper as a fundamental part of the numerical analysis for enhancing and developing the analysis of micro/nano structural systems in which the size-dependent effect plays an important role.

\section{References}

[1] A. Komeili,A. Hamid Akbarzadeh,A. Doroushi and M.
Reza Eslami : "Static Analysis of Functionally Graded Piezoelectric Beams under Thermo-Electro-Mechanical Loads" ,Advances in Mechanical Engineering, 2011

[2] J Yang and H J Xiang, : "Thermo-electro-mechanical characteristics of functionally graded piezoelectric actuators", Smart material and structures, 2007

[3] Jianjun Wang, Zhifei Shi, and Hongjun Xiang: "Electromechanical Analysis of Piezoelectric Beam-Type Transducers With Interlayer Slip", IEEE Transactions on Ultrasonics, Ferroelectrics, and Fr 1768 equency Control, vol. 60, no. 8, 2013

[4] X.Q. Hea, T.Y. Ngb, S. Sivashankera, K.M. Liewa : "Active control of FGM plates with integrated piezoelectric sensors and actuators", ELSEVIER, 2001

[5] T.Y. Ngb, K.M. Liewa : "Active control of FGM plates with integrated piezoelectric sensors and actuators", International Journal of Solids and Structures, 2001

[6] Vanam B.C.L, Rajyalaksmi M. and lnala R. : "Static analysis of an isotropic rectangular plate using finite element analysis(FEM),

[7] L.F. Greimann and P.P. Lynn. : "Finite element analysis of plate bending with transverse shear deformation" ELSEVIER, 1970

[8] C. M. Wang, J. N. Reddy, and K. H. Lee. : "Shear deformable beams and plates", Elsevier, Oxford, 2000

[9] J. N. Reddy and S.D. Pang. Nonlocal continuum theories of beams for the analysis of carbon nanotubes. Journal of applied physics, 103, 2008

[10] V Phunpeng, P. M. Baiz and S. T. Pinho, "Numerical analysis of piezoelectric functionally graded beams", Proceedings of the 20th UK National Conference of the Association for Computational Mechanics in Engineering, 26 $6^{\text {th }}-28^{\text {th }}$ March 2012, University of Manchester, UK 